Portland State University

PDXScholar

3-10-1989

\title{
Attitudes of Control and Weight Management
}

Carolyn Lee Edwards Wright

Portland State University

Follow this and additional works at: https://pdxscholar.library.pdx.edu/open_access_etds

Part of the Health Psychology Commons

Let us know how access to this document benefits you.

\section{Recommended Citation}

Wright, Carolyn Lee Edwards, "Attitudes of Control and Weight Management" (1989). Dissertations and Theses. Paper 3949.

https://doi.org/10.15760/etd.5833

This Thesis is brought to you for free and open access. It has been accepted for inclusion in Dissertations and Theses by an authorized administrator of PDXScholar. Please contact us if we can make this document more accessible: pdxscholar@pdx.edu. 
AN ABSTRACT OF THE THESIS OF Carolyn Lee Edwards Wright for the Master of Science in Psychology presented March 10, 1989.

Title: Attitudes of Control and Weight Management

APPROVED BY THE MEMBERS OF THE THESIS COMMITTEE:

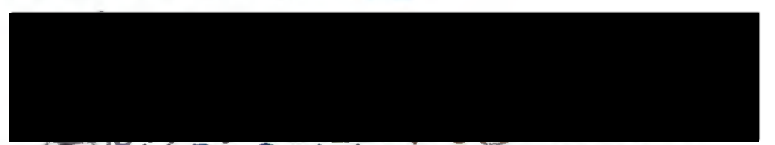

"Gerald D. Guthrie

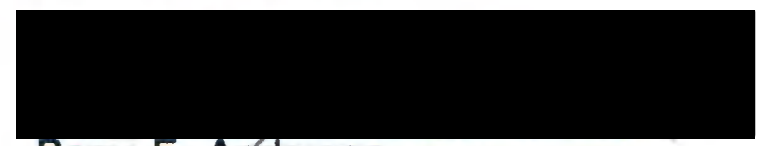

Barry F. Anderson

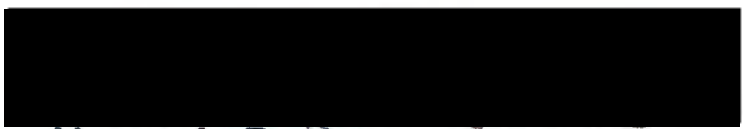

Nancy A. Perkin

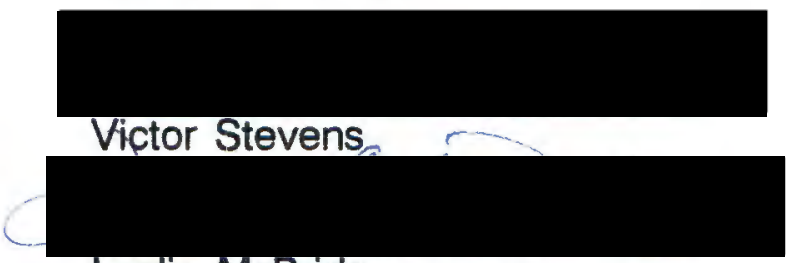

Leslie McBride

Applications of locus of control theory to weight loss programs have yielded inconsistent results. This study attempts to clarify "control" by looking at two different factors. Maximum control is the degree of perceived control inherent in the event itself, and personal control is the degree to which the event is perceived controllable by the individual. These two factors were also examined in two types of situations to determine whether individuals have one global outlook on control, or if they make a distinction between control in some situations as opposed to control in other situations. Seventy-four female 
subjects completed a 16 item questionnaire on their perceived control in weight-related and non-weight-related situations. Subjects demonstrated that attitudes of control are situation specific. The two separate attitudes, maximum control and personal control, operate independently. Some individuals who felt that events were highly controllable, still felt they had very little control. Converse perceptions were also demonstrated. 


\title{
ATTITUDES OF CONTROL AND WEIGHT MANAGEMENT
}

\author{
by \\ CAROLYN LEE EDWARDS WRIGHT
}

A thesis submitted in partial fulfillment of the requirements for the degree of

\author{
MASTER OF SCIENCE \\ in \\ PSYCHOLOGY
}

Portland State University

1989 


\section{TO THE OFFICE OF GRADUATE STUDIES:}

The members of the Committee approve the thesis of Carolyn Lee Edwards Wright presented March 10, 1989.

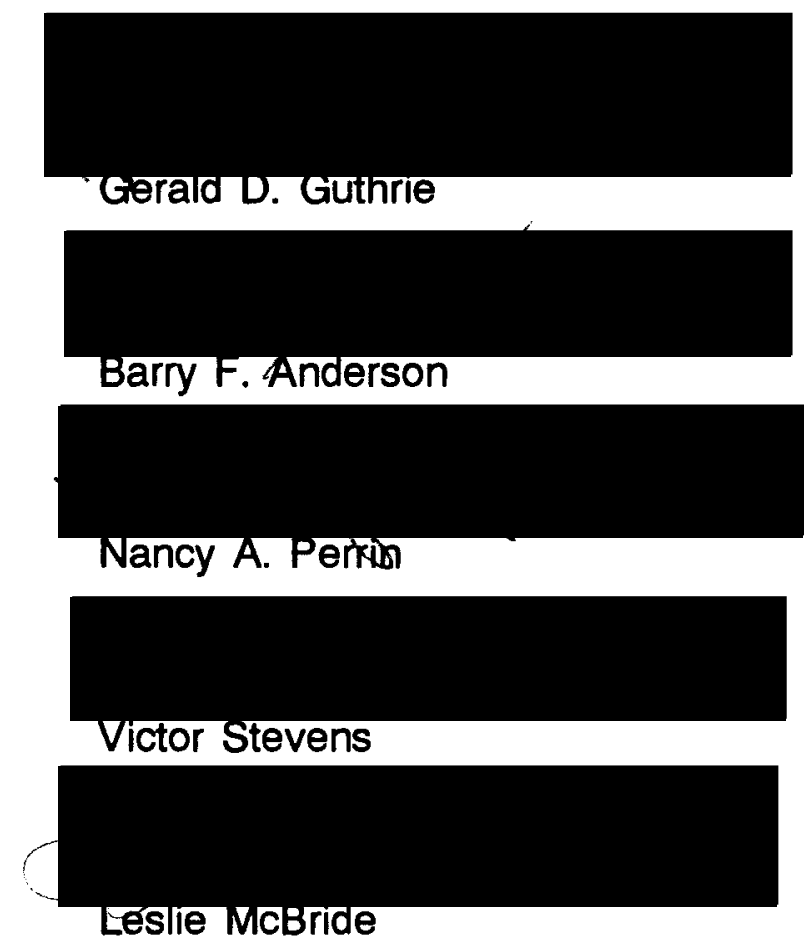

\section{APPROVED:}

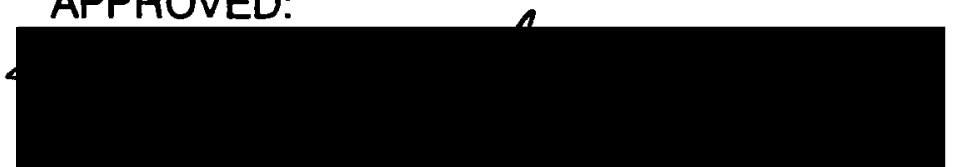

Rogef D. Jennings/Department of Pgychology

C. Villiam Savery, Interim Vice Provost for Graduate Studies and Research 


\section{ACKNOWLEDGEMENTS}

I would like to express my deep appreciation to those individuals who contributed to this project. First, I would like to thank the members of my thesis committee, Dr. Gerald D. Guthrie, chair, Dr. Barry A. Anderson, Dr. Nancy A. Perrin, and Dr. Victor Stevens for the substantial contributions to the project from the genesis of the idea to the completion of the written report.

Second, I would like to thank the many leaders of the Freedom From Fat Program at Kaiser-Permanente Center for Health Research for allowing me to gather data from their program participants.

Third, I would like to thank the many friends, fellow graduate students, and family members who provided emotional support during the last 3 years. 


\section{TABLE OF CONTENTS}

PAGE

ACKNOWLEDGEMENTS $\ldots \ldots \ldots \ldots \ldots \ldots \ldots$. . . . . . . . . . .

LIST OF TABLES $\ldots \ldots \ldots \ldots \ldots \ldots \ldots \ldots \ldots$ vi

LIST OF FIGURES $\ldots \ldots \ldots \ldots \ldots \ldots \ldots \ldots$ vii

INTRODUCTION $\ldots \ldots \ldots \ldots \ldots \ldots \ldots \ldots \ldots \ldots \ldots$

Review of Locus of Control Literature . . . . . . . . . . . . . . . 1

Purposes of This Study $\ldots \ldots \ldots \ldots \ldots$

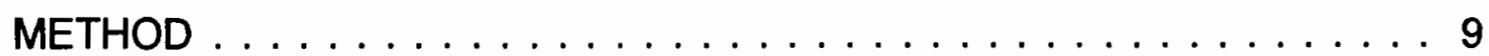

Questionnaire Development . . . . . . . . . . . . 9

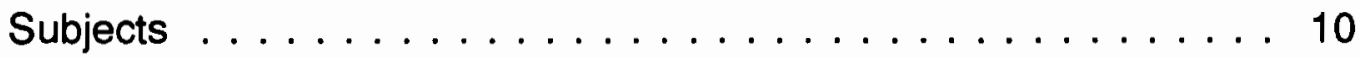

Procedures $\ldots \ldots \ldots \ldots \ldots \ldots \ldots \ldots \ldots \ldots$

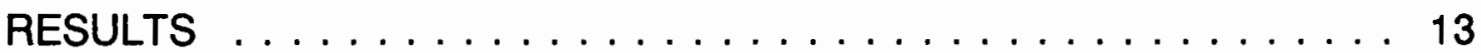

Maximum Control ..................... 13

Personal Control . . . . . . . . . . . . . . . . . . . 14

Consistency of Attitudes of Control . . . . . . . . . . . 18

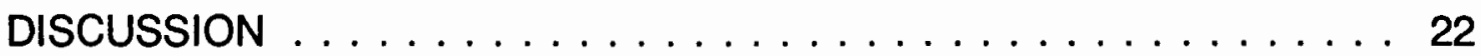

Maximum Control . . . . . . . . . . . . . . . . . . . 22

Personal Control . . . . . . . . . . . . . . . . . . . 23

Consistency of Attitudes of Control . . . . . . . . . . . . . . . . 24

Implications ....................... 25 


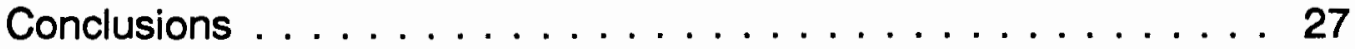

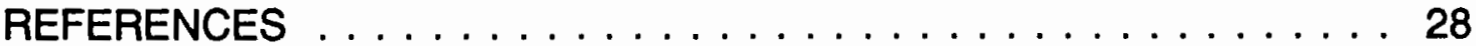

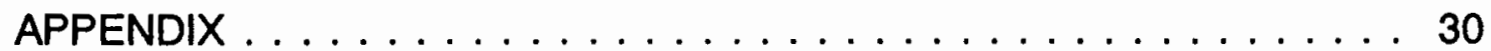




\section{LIST OF TABLES}

PAGE

\section{TABLE}

I Analysis of Maximum Control . . . . . . . . . . . . 14

II Means (M) and Standard Deviations (SD) for Maximum Control of Non-weight-related Issues and Maximum Control of Weight-related Issues $\ldots \ldots \ldots \ldots \ldots \ldots \ldots$

III Analysis of Personal Control $\ldots \ldots \ldots \ldots \ldots \ldots \ldots$

IV Means and Standard Deviations for Personal Control of Non-weight-related Issues and Personal Control of Weight-related issues . . . . . . . . . . . 17

$\checkmark$ Distribution of Subjects According to Combined Designations of High and Low Maximum and Personal Control ..................... 18

VI Chi-Square Values with Yates Correction and Probabilty that Apparent Relationsships Occurred By Chance . . . . . . 19 


\section{LIST OF FIGURES}

PAGE

\section{FIGURES}

1. Mean Scores of Subjects by Group for Personal and

Maximum Control on Weight and Non-weight-related Issues . . . 20 


\section{INTRODUCTION}

Treatment of obesity is one of the most difficult of therapeutic undertakings. (Obesity is usually defined as being $50 \%$ above ideal weight, see Wadden, et al. [1984]). Brownell (1984) likens the success of the treatment of obesity to the treatment of cancer and says, "a person is more likely to recover from many forms of cancer than from obesity." (p. 406). The incidence of overweight is increasing. As cited in Foreyt (1987), data furnished by the Division of Health Examination Statistics in 1985 indicate that obesity is becoming more prevalent in most segments of the population.

Different types of weight loss programs have proven successful for some individuals (Brownell, 1986). But as Stunkard (1987) notes, many individuals do not remain in treatment programs long enough to succeed.

A method for identifying factors which would help match individuals with the type of program most likely to provide success for them, and/or which would identify factors which individuals who complete programs have in common, would appear to be useful.

\section{REVIEW OF LOCUS OF CONTROL LITERATURE}

Personality Variables

There have been repeated attempts to identify personality characteristics which will predict success in weight loss programs. 
Locus of Control

In early writings, Rotter (1966) defined what he termed "locus of control" (LOC) as a one-dimensional factor which had a global effect. Individuals could be described as Internal (I) if they attributed the control of reinforcement to their own actions. Externals $(E)$ attributed control of reinforcement to outside factors--chance, powerful others, etc. Further, the way individuals attributed causes of outcomes influenced their behavior in future situations.

Many studies have shown that Internals and Externals behave differently in various ways. (e.g. Gregory, Chartier and Wright (1979) [for reactions to escapable and inescapable aversive events]; Pittman and Pittman (1979) [on helplessness training]; Furnham, Hillard and Brewin (1985) [for Type A behavior and LOC.])

A number of studies have attempted to show a relationship between LOC and weight control. The results have been contradictory. Chambliss and Murray (1979) reported a significant correlation between type of treatment program and LOC. Bolocofsky et al. (1984) found that individuals who lost weight in a program tended to be more internal in LOC than those who dropped out of the weight control program, although this factor was less significant than initial weight, age at onset of obesity and several other factors tested, including Factors $\mathrm{C}$ (emotional stability), $\mathrm{N}$ (forthrightness) and $\mathrm{O}$ (selfassurance) from the Cattel Sixteen Personality Factor Questionnaire. Balch 
and Ross (1975) found a significant correlation between Rotter I-E scores and completion of a weight loss program.

However, Gormanous and Lowe (1975) were unable to establish any correlation between locus of control scores and obesity. In a comparison of two types of behavioral weight reduction programs (Bellack, et al. 1974) researchers found that LOC was not a significant factor in predicting which individuals would succeed, that is, lose weight, in the programs.

Tobias and MacDonald (1977), referring to a behavioral treatment of obesity, state that personal responsibility, as measured by a Rotter I-E scale, was insufficient to instigate weight loss.

In a study on weight loss maintenance over time, Bernier and Poser (1984) found that self-efficacy, which is defined as a perceived sense of mastery or control (Goldfried and Robins, 1982), was a reliable predictor of weight maintenance. Subjects were not identified specifically as to placement on a Rotter I-E scale, but those individuals who expressed a higher perceived sense of control on a 10 item questionnaire of efficacy expectations were the most successful in maintaining a weight loss.

In summary, a review of the literature indicates that LOC has not been shown to be a reliable predictive factor for whether or not an individual will begin a weight loss program, lose weight, or maintain the weight loss. 
Questions of Consistency

The contradictory LOC data are puzzling. A possible answer may lie in the question of variation in I-E scores within individual subjects. The previously cited authors appear to assume that individuals score consistently in one direction or the other on LOC scales, that an individual has one global outlook on the control of reinforcement. LOC scores are obtained by totaling a subject's responses over a variety of topics. (Eating behaviors, nutritional habits, or exercise patterns are not represented in the topics.) The total score, without regard to the different types of situations represented, is used for identification of internally and externally focused individuals.

Global or specific attitudes of control

Is it possible that individuals may feel in control of some areas of functioning and not in control of others? Specifically, could some overweight individuals generally feel in control in personal relationships or employment concerns, for instance, and yet not feel in control in matters involving diet, exercise and weight loss? If this the case, then a general measurement of locus of control is apt to provide placement on a locus of control scale unrelated to the specific problem under consideration. If only weight-related attitudes affect weight control, then it is not surprising that measurement of control in other types of situations will have no predictive value. 
Maximum versus personal control

It further appears that the issue of control really involves factors which may be analogous to Bandura's (1982) concepts of outcome expectancy and self-efficacy expectancy. In Bandura's model, individuals must decide first how likely it is that the proposed course of action will result in the desired result. This is called outcome expectancy. Then, they must decide how likely it is that they are capable of accomplishing that course of action if they decide it is worthwhile. This is called self-efficacy expectancy.

Similar to Bandura's model, in the concept of control, individuals must also take two different factors into consideration when making judgments. First of all, how much control is possible for anyone in that situation? Similar to Bandura's concept of outcome expectancy, this determination focuses on the perceived charateristic of the event itself, although it may appear earlier in the decision process. For example, the individual has to decide if it is ever possible to lose weight through any personal effort (maximum control) before he/she can decide on the merits of a specific weight loss program (outcome expectancy).

Secondly, how much control can they personally exert? This is analogous to self-efficacy expectancy. It may be possible for an individual to believe that the situation is controllable to a high degree for others, but not for him/herself. It may also be possible for an individual to decide that the situation, generally, is not subject to control, but that he/she can control it as much as anyone. 
For instance, one individual may believe that attaining a state of good health is completely controllable through behaviors such as controlling weight, exercising, quitting smoking, etc. and yet believe that he is personally powerless to make these changes in his own lifestyle. Another individual may believe that while he could personally control such behaviors as smoking, dieting, and exercising, good health is really dependent on having inherited a strong constitution and making lifestyle changes would not be worthwhile. While both individuals would exhibit the same behaviors (they both smoke, neglect diet and exercise), the reasons behind those behaviors would be very different and would necessitate different treatment strategies.

\section{PURPOSES OF THIS STUDY}

There are three major questions which will be examined in this study. One question concerns the possibility of two types of perceived control, maximum control and personal control. The second question is whether locus of control is a global attitude, or if attitudes of perceived control are specific to situations. The third question will address the issue of consistency between the two different types of perceived control in the individual.

\section{Maximum Control}

One area of investigation in this study is situation specific attitudes of maximum control. The specific attitude we have chosen to look at concerns weight-related issues versus non-weight-related issues. (Weight-related issues 
are those involving exercise, choice of food items, eating patterns, etc. Nonweight-related issues include controlling temper, use of leisure time, mood, etc.)

Hypothesis I is: Individuals will differ in the way they perceive maximum control possible between weight-related issues and non-weight-related issues according to weight groupings. Individuals who are more overweight will perceive less maximum control possible in weight-related issues than in nonweight related issues, while those who are close to ideal weight will show little difference in maximum control possible between weight- and non-weightrelated issues.

\section{Personal Control}

The second question which will be addressed is that of personal control. Is the current degree of overweight negatively correlated with feelings of personal control on weight-related issues?

Hypothesis II is: Individuals will demonstrate differences in perceived personal control between weight-and non-weight-related issues according to weight groupings. Those individuals closest to ideal weight will show little or no difference in perceived personal control and those individuals who are $50 \%$ or more over ideal weight will demonstrate significant differences in perceived personal control. 
Consistency of Attitudes of Control

The third question will address the issue of consistency between attitudes of maximum control and attitudes of personal control within individuals. Since it is possible that attitudes of control may be separated into personal and maximum factors, then it is also possible that these two factors may operate independently within individuals.

As stated previously, it is conceivable that individuals do not necessarily have to be consistent by demonstrating both high personal control and high maximum control, or low personal control and low maximum control. Four possible combinations of attitudes of high $(H)$ and low $(L)$ are possible on the two factors.

1. An individual may believe that events are highly controllable and he/she has high personal control. This individual would be designated $\mathrm{HH}$.

2. An individual may believe that events are not very controllable and that the individual does not even have personal control over what is. This individual would be designated LL.

3. An individual may believe that a situation is highly controllable for others, but not for him/herself. This individual would be designated HL.

4. An individual may decide that the situation, generally, is not subject to control, but that he/she can control it as much as anyone. This individual would be designated $\mathrm{LH}$.

Hypothesis III is: Individual perceptions of maximum and personal control are independent of each other. 


\section{METHOD}

\section{QUESTIONNAIRE DEVELOPMENT}

Existing locus of control instruments do not address either the maximum versus personal control issue or the global versus specific issue. So a new instrument was devised.

Initially, 60 items were generated for reliability testing. Half were weight-related and half were non-weight-related. Weight-related items covered topics of nutrition, attitudes toward exercise, and eating habits. Non-weight items addressed a number of issues, including stress, mood, and personal relationships.

A scoring system was devised to ascertain three different types of attitudes of control. Maximum and personal control were used, as defined here. In addition, control by an "average person" was included.

It was expected that the subjects would indicate average and personal control in relation to maximum control. That is, if an event were thought to be $70 \%$ controllable on the maximum scale, then average and personal control would be indicated as some portion of that $70 \%$, but not a higher figure.

In a test study among a population ( $n=275)$ of college students, approximately $25 \%$ of the questionnaires were found to be invalid because 
subjects indicated higher personal or average control than they had given for maximum control.

Two hundred valid questionnaires were subjected to a split-half reliability procedure. The sixteen tests items (half weight- and half non-weightrelated) with the highest phi co-efficients, all .30 or above, were then subjected to a Kuder-Richardson test for reliability. The reliability was .96 for the maximum control scale and .96 for the personal control scale.

Since the proposed population for the study was limited, it was felt that a possible loss of $25 \%$, as had occurred in the test group, was too risky. The questions remained the same, but the response system was revised and implified. First, the "average" control question was eliminated. Second, the two remaining scales, maximum control and personal control, were made independent of each other. Third, instructions were included which directed the subjects to compare themselves, not to a mythical average, but to individuals known to them.

The revised questionnaire consisted of 16 ( 8 weight-and 8 non-weightrelated) items and a personal information inventory. (See Appendix A.)

\section{SUBJECTS}

One hundred and five female volunteers were recruited from two populations, the Kaiser-Permanente Freedom From Fat (FFF) program, a behaviorally oriented weight loss program in the Portland, Oregon area, and from an introductory psychology course at Portland State University, Portland, Oregon. 


\section{PROCEDURES}

The 16 item testing instrument described previously was administered to the subjects. After completing the questionnaire, all subjects completed a short personal information survey. Questions included age, height, present weight, subject's estimation of her ideal weight, weight history, and estimate of experienced stress.

From the information on the personal inventory, subjects were classified by their percentage overweight. Each subject had provided her estimate of her ideal weight and her current weight. Since the study was concerned with perceived attitudes, the subjects' perceptions of their own ideal weights were used, instead of standard weight tables in determining amount of overweight. The number of pounds in excess of ideal weight was divided by ideal weight and multiplied by 100 . Group I $(n=9)$ were those individuals from FFF who were no more than $10 \%$ above their ideal weight, Group II $(n=19)$ were those individuals from FFF who were $25-40 \%$ above ideal weight, and Group III $(n=20)$ those individuals from FFF who were $50 \%$ or more above ideal weight. Group IV $(n=26)$ were PSU subjects in the $0-10 \%$ of ideal weight range. This group, because they were not involved in a weight loss program, served as a control group. There were no subjects who weighed less than the expressed ideal weight.

Data from those subjects who were $11-24 \%$ or $41-49 \%$ overweight were not used in the analysis of variance in order to give definition to the 
groups. Data from all 105 subjects were used in the multiple linear regression analysis.

The information from the questionnaire provided two scales of subject opinions. Subjects were asked to indicate the maximum amount of control (scale M) they believed would be possible for anyone to exert in a given situation. On the second scale (scale P) subjects were asked to indicate the amount of control they believed they, personally, could exert in the same situation.

The median score for Maximum control (combined weight- and nonweight-related issues) and for Personal control (combined weight-related and non-weight-related issues) was determined for the control group. Using these figures, each subject in the population used in the ANOVA was identified as either above ( $H$ for high) the median or below ( $L$ for low) the median on each scale.

Subjects were then designated $\mathrm{HH}$ if they were above the median on both scales, $\mathrm{LL}$ if they were below the median on both scales, or $\mathrm{HL}$ or $\mathrm{LH}$ if above on one and below on the other. 


\section{RESULTS}

\section{MAXIMUM CONTROL}

A $2 \times 4$ Analysis of Variance was used to obtain F scores for the weight-related versus non-weight-related attitudes of Maximum control (the within subjects score), for the different groups (the between groups score), and for the interaction between the groups and the issues scales.

On the M scale, maximum control possible, all subjects differentiated between weight- and non-weight-related issues, $\underline{F}(3,70)=22.98$, p. $<001$ level. There was a significance between groups, $\underline{F}(3,70)=3.78$, p. $<.025$. There was no significant groups-by-lists interaction. (See Table I.)

The prediction according to Hypothesis I was that subjects would differ in attitudes of the maximum controllability of events between weight- and nonweight-related issues according to groups. It was expected that the subjects closest to ideal weight would not demonstrate awareness of a difference between the two lists. However, not only did all subjects demonstrate an awareness of the difference between the two lists, but all subjects indicated that weight-related items were more controllable than non-weight-related items. The difference noted between the groups occurred because Groups 
TABLE I

ANALYSIS OF MAXIMUM CONTROL

\begin{tabular}{lrcccc}
\hline Source & SS & df & ms & $\underline{F}$ & $P$ \\
\hline Total & 15769 & 147 & -- & -- & -- \\
Between subjects & 10652 & 73 & -- & -- & -- \\
Groups & 1485 & 3 & 495 & 3.78 & $<.025$ \\
Error b & 9167 & 70 & 130.96 & -- & -- \\
Within Subjects & 5117 & 74 & -- & -- & -- \\
Issues & 1197 & 1 & 1197 & 22.98 & $<.001$ \\
Issues $x$ Groups & 274 & 3 & 91.3 & 1.75 & $<.20$ \\
Error w & 3646 & 70 & 52.1 & &
\end{tabular}

Groups I $(0-10 \%)$ and III $(50 \%+)$ perceived significantly higher maximum control than Group IV (Control) did. (See Table II.)

\section{PERSONAL CONTROL}

A $2 \times 4$ Analysis of Variance was used to obtain F scores for the nonweight related versus weight-related attitudes of Personal control (the within subjects scores), for the different groups (the between groups score), and for the interaction between the groups and the issue scales. On the P scale, personal control, there was an interaction between lists and groups, 
TABLE ॥

MEANS (M) AND STANDARD DEVIATIONS (SD) FOR MAXIMUM CONTROL OF NON-WEIGHT-RELATED ISSUES AND MAXIMUM CONTROL OF WEIGHT-RELATED ISSUES

\section{Maximum Control}

$\frac{\text { Non-weight }}{\mathrm{M}} \quad$ WD Weight

$\begin{array}{llllr}\text { Group I } & 61.44 & 11.63 & 70.11 & 7.14 \\ \text { Group II } & 60.5 & 8.52 & 66.05 & 9.55 \\ \text { Group III } & 60.0 & 9.52 & 67.74 & 10.81 \\ \text { Group IV } & 55.88 & 6.89 & 59.15 & 11.73\end{array}$

E, $(3,70)=2.99$, p. $<.05$ level. (See Table III.)

Post hoc tests determined that the difference in attitudes of personal control on non-weight questions between groups occurred between Group I $(0-10 \%)$ and all other groups. The Newman-Keuls Multiple Range test was used. Differences of 13.2 between Groups I (0-10\%) and II (25-40\%), 13.4 between Groups I (0-10\%) and III (50\% +), and 13.9 between Groups I (0$10 \%)$ and IV (Control) were significant at the .05 level. There were no significant differences between any other pairings of groups.

Analysis of the responses to the weight-related questions with the Newman-Keuls Multiple Range test showed that differences of 18.4 between 
TABLE III

ANALYSIS OF PERSONAL CONTROL

\begin{tabular}{lrrccc}
\hline Source & SS & df & ms & F & P \\
\hline Total & 25872 & 147 & -- & -- & -- \\
Between Subject & 21399 & 73 & - & - & - \\
Groups & 4524 & 3 & 1508 & 6.25 & $<.001$ \\
Error b & 16875 & 70 & 241.1 & - & - \\
Within Subjects & 4473 & 74 & -16 & - & - \\
Issues & 6 & 1 & 6 & .11 & $>.20$ \\
Issues x Groups & 506 & 3 & 169 & 2.99 & $<.05$ \\
Error w & 3961 & 70 & 56.59 & -- & -
\end{tabular}

Groups I (0-10\%) and II (25-40\%), 8.9 between Groups III $(50 \%+)$ and IV (Control), 23.6 between Groups I (0-10\%) and III (50\% +), and 14.7 between Groups I (0-10\%) and IV (Control) were significant at the .05 level. Means and standard deviations are shown in Table IV.

Predictions according to Hypotheses II were that subjects would demonstrate differences in attitudes of personal control between weight- and non-weight-related issues according to weight groups. The direction of the scores was consistent. Groups I and IV, the two groups of subjects who were within $10 \%$ of ideal weight, perceived higher personal control on weight- 
TABLE IV

MEANS (M) AND STANDARD DEVIATIONS (SD) FOR

PERSONAL CONTROL OF NON-WEIGHT-RELATED

ISSUES, AND PERSONAL CONTROL OF

WEIGHT-RELATED ISSUES

Personal Control

Non-weight

Weight

M

SD

M

SD

Group 1

62.44

10.66

67.33

09.89

Group II $\quad 49.2$

11.28

48.6

14.81

Group III

49.05

10.49

43.37

13.58

Group IV

49.65

11.11

52.35

12.19

-related issues than on non-weight-related issues. Groups II and III, the two groups of subjects who were at least $25 \%$ overweight, perceived lower personal control of weight-related issues than of non-weight-related issues.

Additionally, data from all 105 respondents were subjected to a multiple linear regression analysis. The dependent variable was percent overweight (OW). This variable was predicted from the four different control variables; NM (non-weight-related maximum control, NP (non-weight-related personal control), WM (weight-related maximum control), and WP (weight-related personal control. The standardized regression equation (OW $=-.038 \mathrm{NM}+$ $.077 \mathrm{NP}+.300 \mathrm{WM}+-.393 \mathrm{WP})$ had a corresponding $\mathrm{R}$ square $=.173, \mathrm{E}_{,}(4$, 100) p. <.001. Both maximum and personal control of weight-related issues contributed significantly to the model, but the 2 non-weight control variables 
did not. Maximum control of weight-related issues was positively correlated with percentage of overweight. As predicted, personal control attitudes were negatively correlated with percentage of overweight.

\section{CONSISTENCY OF ATTITUDES OF CONTROL}

The distribution of all subject descriptions by combining perceived maximum control and perceived personal ( $\mathrm{HH}, \mathrm{HL}, \mathrm{LH}$ or $\mathrm{LL})$ is contained in Table V.

\section{TABLE V}

DISTRIBUTION OF SUBJECTS ACCORDING TO COMBINED

DESIGNATIONS OF HIGH AND LOW MAXIMUM AND PERSONAL CONTROL

\begin{tabular}{lcccc}
\hline & $\begin{array}{c}\text { Group } \\
\text { I }\end{array}$ & $\begin{array}{c}\text { Group } \\
\text { II }\end{array}$ & $\begin{array}{c}\text { Group } \\
\text { III }\end{array}$ & $\begin{array}{c}\text { Group } \\
\text { IV }\end{array}$ \\
\hline $\mathrm{HH}$ & 7 & 9 & 6 & 6 \\
$\mathrm{HL}$ & 1 & 8 & 8 & 7 \\
$\mathrm{LH}$ & 1 & 1 & 0 & 7 \\
$\mathrm{LL}$ & 0 & 2 & 5 & 6
\end{tabular}

HH stands for high maximum control and high personal control

HL stands for high maximum control and low personal control

LH stands for low maximum control and high personal control

LL stands for low maximum control and low personal control 
Chi-square values were calculated for each group to test whether the attitude of personal control was related to the attitude of maximum control with the results shown in Table VI. (The Yates correction was used because of fixed marginal probabilities in Group IV and because of low cell numbers in all the groups.) The highest chi-square occurred with Group I and corresponded to a probability on the order of .2 that any relationship between the two was due to chance. All the other chi-square values had probabilities of .8 or more that any relationship was due to chance.

Therefore, we cannot reject the null hypothesis of independence. However, because of the small numbers in the chi-square cells, the power of the test is low.

\section{TABLE VI}

\section{CHI-SQUARE VALUES WITH YATES CORRECTION AND PROBABILITY THAT APPARENT RELATIONSHIPS OCCURRED BY CHANCE}
Chi-square
Probability

Group I $\quad 1.72 \quad .2$

$\begin{array}{lll}\text { Group II } & 0.036 & .8\end{array}$

Group III $\quad 0.044 \quad .8$

$\begin{array}{lll}\text { Group IV } & 0.0 & .99\end{array}$

The prediction of Hypothesis III that perceived maximum and perceived personal control operate independently is suggested from the data, but not clearly demonstrated. 
The means for weight-and non-weight responses in both maximum control and personal control are graphed in Figure 1.
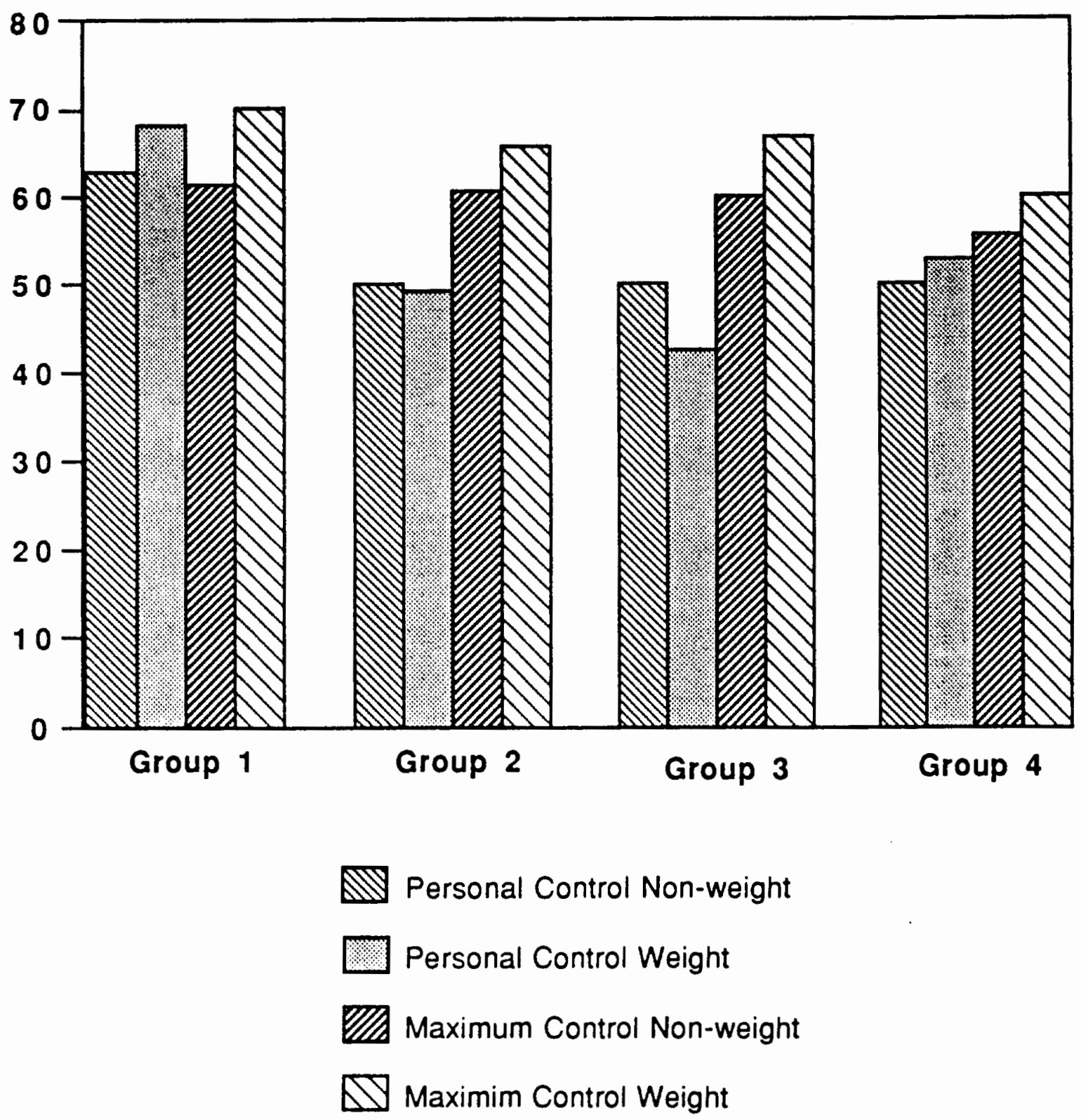

Figure 1. Mean scores of subjects by group for personal and maximum control on weight- and non-weight-related issues. 
The differences in the relative position of the three FFF groups compared to the control group in the two areas demonstrates the importance of making a distinction between maximum control and personal control. 


\section{DISCUSSION}

There has been some experimental evidence for the concept of locus of control. In the field of weight control and management, the data have not been consistent. As previously cited, some studies have shown locus of control as a significant factor in predicting weight loss and weight maintenance. Other studies have shown no significance for locus of control as a predictive factor.

The findings of this study may offer some answer to the problems of inconsistency in LOC studies.

\section{MAXIMUM CONTROL}

All subjects discriminated between the two types of issues, and all subjects perceived weight-related issues as being more controllable than nonweight related issues.

It was clearly demonstrated that subjects make distinctions according to specific situations. This would call into question the accuracy of LOC designations based on the average of responses to a number of different issues. 


\section{PERSONAL CONTROL}

The differences in perceived control can be summarized as follows: The subjects in Group I (0-10\%) demonstrated significant differences from all other subjects on both weight- and non-weight-related issues. They perceived higher personal control on all issues. There were no significant differences of perceived control among any of the other groups on non-weight related issues. Group III $(50 \%+)$ subjects demonstrated significant differences from Group I (0-10\%) and Group IV (Control) on weight-related issues. Group III $(50 \%+)$ demonstrated significantly lower perceived control on weight-related issues.

Although other group differences were not statistically significant, their groups means were found to be arrayed in the predicted direction. Groups I and IV, who were within $10 \%$ of ideal weight, expressed higher personal control than either of the groups of overweight subjects. In addition, both groups of subjects who were within $10 \%$ of their ideal weight indicated higher personal control on weight-related issues than on non-weight-related issues, while both groups of subjects who were overweight indicated lower personal control of weight-related issues than non-weight-related issues.

It is probable that the difference in Personal control between Group I and the other groups can be attributed to Group I subjects' experience in the Freedom From Fat program. Group I consisted of individuals who had been overweight and had reached $0-10 \%$ above ideal weight as a result of the weight management program. 
It is not possible to determine from this study whether perceptions of personal control preceded the weight loss, or succeeded it. Work by Bernier and Poser (1984) suggest that feelings of self-efficacy (personal control) can be increased by instruction in attributing success to personal effort. Thus, success in the weight loss program could have increased feelings of personal control.

\section{CONSISTENCY OF ATTITUDES OF CONTROL}

One of the hypotheses of this study was that individuals could perceive the degree of maximum control and the degree of personal control independently. This was indicated. (See Table V.)

This comparison was valuable because it allowed both maximum control and personal control, which had been analyzed separately before, to be considered in relation to each other.

It also allowed a comparison between the population sample of college students, and the subjects who had chosen to participate in a weight management program. With the ability to look at how the two factors were related in each group, it was then possible to note the differences between FFF groups and the control group. This comparison provided one of the most interesting findings of the study, namely that being within a normal weight range per se, was not predictive of control attitudes.

It is obvious from the array of the maximum/personal control relationship that a major difference between the control group and the weight 
management groups is in the attitude of maximum control. Most of the FFF subjects were in the high perceived maximum control area, regardless of perceived personal control level. (See Table V.)

\section{IMPLICATIONS}

There are many questions still to be asked and further investigation is warranted. A major limitation of this study, of course, is the fact that there was only one contact with the subjects. There was no way to determine whether (or how) attitudes of control changed for the FFF subjects over the course of the weight treatment program. Was the difference in the proportion of subjects in Group I and Group II demonstrating high maximum control indicative of a sorting process in the treatment program? Is there a commonality in attitudes of maximum control in individuals who do not complete the program? If so, what or in what direction?

Some of the basic issues which should be examined further are:

1. Consistency of maximum control attitudes in the general population of overweight individuals. It could easily be supposed that behavioral weight treatment programs are populated by individuals who have "sorted" themselves out of the general population. Individuals demonstrate increased perception of maximum control or outcome expectancy in a very practical way by enrolling in the program and paying the fee. Do overweight individuals in the general population fall into the 4 categories of the maximum/personal 
control model? And are only those individuals with higher than average feelings of maximum control attracted to behavioral treatment programs?

2. Possibility of attitudes of personal control as a predictive factor. The multiple linear regression analysis indicates that percent of overweight indicates lower feelings of personal control as amount of overweight increases, but it is impossible to tell from this study if the increase in the attitude of personal control in Group I subjects is completely due to success in losing weight or if there is an attrition factor.

It is not clear from research previously cited if data from subjects who dropped out of programs were examined. If there is a difference in pretreatment attitudes between those who are successful and those who do not complete a program, this could be a useful predictor.

3. Changes in attitudes of maximum control. It has been demonstrated that changes in self-efficacy occur with experience and instruction in making personal effort attributions for success. Is it possible to change attitudes of maximum control as well? Under what circumstances could those changes be accomplished? And more importantly, is there an advantage, in terms of treatment completion or weight control or weight maintenance, in increasing perception of maximum control? 


\section{CONCLUSIONS}

The impetus for this study was a desire to clarify factors which might lead to a reliable predictor of success in weight treatment programs. Perhaps the identification of the variations that can occur in the relationship between maximum control and personal control will be a step in that direction. 


\section{REFERENCES}

Balch, P., \& Ross, A.W. (1975). Predicting success in weight reduction as a function of locus of control: a unidimensional and multidimensional approach. Journal of Counseling and Clinical Psychology, 43(1), 119.

Bandura, A. (1982). Self-efficacy mechanism in human agency. American Psychologist, 37(2), 122-147.

Bellack, A.S., Rozensky, R., \& Schwartz, J. (1974). A comparison Of two forms of self-monitoring in a behavioral weight reduction program. Behavior Therapy, $\underline{5}, 523-530$.

Bernier, M., \& Poser, E.G. (1984). The relationship between self- efficacy, attributions, and weight loss in a weight Rehabilitation program. Journal of Rehabilitation Psychology, 29(2), 95-105.

Bolocofsky, D.N., Coulthard-Morris, L., \& Spinler, D. (1984). Prediction of successful weight management from personality and demographic data. Psychological Reports, 55, 795-802.

Brownell, K. D. (1984). The psychology and physiology of obesity: implications for screening and treatment. Journal of the American Dietetic Association, 84(4), 406-414.

Brownell, K. D. (1986) Public health approaches to obesity and management. Annual Review of Public Health, $\underline{7}, 531-533$.

Chambliss, C. A., \& Murray, E.J. (1979). Efficacy attribution, locus of control, and weight loss. Cognitive Therapy and Research, 3(4), 349-353.

Foreyt, J. P., (1987) Issues in the Assessment and Treatment of Obesity. Journal of Consulting and Clinical Psychology, 55(5), 677-684.

Furnham, A., Hillard, A., \& Brewin, C. R. (1985). Type A behavior pattern and attributions of responsibility. Motivation and Emotion, 9(1), 39-51.

Goldfried, M.R., and Robins, C. (1982). On the facilitation of self-efficacy. Cognitive Therapy and Research, 6(4), 349-353.

Gormanous, G. K., \& Warren, C. L. (1975). Locus of control and obesity. Psychological reports, $37,30$. 
Gregory, W. L., Chartier, G. M., \& Wright, M. H. (1979). Learned helplessness and learned effectiveness: effects of explicit response cues on individuals differing in personal control expectancies. Journal of Personality and Social Psychology, 37(11), 1982-1992.

Pittman, N. \& Pittman, T. (1979). Effects of amounts of helplessness training and internal-external locus of control on mood and performance. Journal of Personality and Social Psychology, 37(1), 39-47.

Rotter, J. (1966) Generalized expectancies for internal versus external control of reinforcement. Psychological Monographs, 80(1, Whole No. 609).

Stunkard, A. J. (1987) Conservative treatments for obesity. American Journal of Clinical Nutrition, $45,1142-1154$.

Tobias, L. \& MacDonald, M. (1977) Internal locus of control and weight loss: an insufficient condition. Journal of Consulting and Clinical Psychology, 45(4), 647-653.

Wadden, T.A., Stunkard, A.J., Brownell, K.D., and Day, S.(1984). Treatment of obesity by behavior therapy and very low calorie diet: a pilot investigation. Journal of Consulting and Clinical Psychology, 52(4), 692-694. 


\section{APPENDIX}

SAMPLE QUESTIONNAIRE 


\section{ATTITUDES OF CONTROL}

\section{INSTRUCTIONS}

This survey is designed to measure attitudes of control in different situations. For instance, some people are healthier than others. There are several ways of explaining this fact.

1. One person may believe that good health all depends on certain actions, such as exercising, taking vitamins, getting enough rest.

2. Another person may believe that good health is simply a matter of having a naturally healthy body. You either have it or you don't.

3. Another person may believe that you start with what you are born with, but after that what you do can make a big difference.

The first person might say that he has complete control of how healthy he is, the second person might say he had no control at all over how healthy he is, and the third person might say that he had $50 \%$ control over how healthy he is.

We are interested in your opinions of how controllable certain events are by people in general, and then how much control you believe you, personally, have in these situations.

An item based on the example above, would appear like this:

1. Some people are healthier than others. What is the maximum possible control anyone could ever have over how healthy he/she is?

Almost

no control
Almost

complete control

\begin{tabular}{lllllllllll}
0 & 1 & 2 & 3 & 4 & 5 & 6 & 7 & 8 & 9 & 10 \\
\hline
\end{tabular}

Compared to your family, friends and co-workers how much control do you feel you actually have over how healthy you are?

Much

Less

0

Same

Much

More 
You answer the questions by circling the number that gives your opinion of the degree of control for that situation.

Please do not place your name on this form. This is your assurance that your answers are completely anonymous. Thank you very much for your time and cooperation. 


\title{
ATTITUDES OF CONTROL
}

1. A major factor in situations such as job success or a happy marriage is the ability to communicate well. What is the maximum possible control the most skillful person could have over communications with other people?

Almost

no control
Almost

complete control

\begin{tabular}{lllllllllll}
0 & 1 & 2 & 3 & 4 & 5 & 6 & 7 & 8 & 9 & 10 \\
\hline
\end{tabular}

Compared to your family, friends and co-workers, how much control do you have over how well you communicate with other people?

Much

Less

Same

Much

More

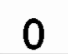

1

\begin{abstract}
2
\end{abstract}
3

4

5

6

7

8

9 10

2. One reason for gaining weight is that TV advertisements make high calorie foods so attractive. What is the maximum possible control the most strongwilled person could have over how much TV influences food choices?

Almost

no control
Almost complete control

\begin{tabular}{lllllllllll}
0 & 1 & 2 & 3 & 4 & 5 & 6 & 7 & 8 & 9 & 10 \\
\hline
\end{tabular}

Compared to your family, friends and co-workers, how much control do you have over how much TV influences your food choices?

Much

Less

Same

Much

More

2

3

4

5

6

7

89

10 
page 2

3. Sometimes people are unhappy because they have bad moods. What do you believe is the maximum control that anyone could have over moodiness?

Almost

no control
Almost

complete control

\begin{tabular}{lllllllllll}
0 & 1 & 2 & 3 & 4 & 5 & 6 & 7 & 8 & 9 & 10 \\
\hline
\end{tabular}

Compared to your family, friends and co-workers, how much control do you have over your moods?

Much

Less
Same

Much

More

\begin{tabular}{lllllllllll}
0 & 1 & 2 & 3 & 4 & 5 & 6 & 7 & 8 & 9 & 10 \\
\hline
\end{tabular}

4. Some people feel stressed because they have too many responsibilities. What is the maximum possible control anyone could have over the amounts and kinds of personal responsibilities?

Almost

no control
Almost complete control
0

2

3

4

5

6

7

8

9

10

Compared to your family, friends and co-workers, how much control do you have over the amount and kinds of responsibilities you have?

Much

Less

Same

Much

More

\begin{tabular}{lllllllllll}
0 & 1 & 2 & 3 & 4 & 5 & 6 & 7 & 8 & 9 & 10 \\
\hline
\end{tabular}


page 3

5. Some people gain weight because of their eating habits. What is the maximum amount of control the most strong-willed person could have over changing eating habits?
Almost
Almost
no control
complete control

\begin{tabular}{lllllllllll}
0 & 1 & 2 & 3 & 4 & 5 & 6 & 7 & 8 & 9 & 10 \\
\hline
\end{tabular}

Compared to your family, friends and co-workers, how much control do you have over these kinds of habits?
Much
Less
Same
Much
More

0

12

3

4

5

$6 \quad 7$

8

9

10

6. Sometimes people are unhappy because they are around people who are unpleasant. What is the maximum amount of control even the most cheerful people can have over their own moods in the presence of unpleasant people?

Almost

no control
Almost

complete control

\begin{tabular}{lllllllllll}
0 & 1 & 2 & 3 & 4 & 5 & 6 & 7 & 8 & 9 & 10 \\
\hline
\end{tabular}

Compared to your family, friends and co-workers how much control do you have over your own mood in the presence of unpleasant people?

Much

Less

Same

Much

More

0

1

2

3

$4 \quad 5$

6

7

8

9 10 
page 4

7. One cause of problems with other people is minor irritations. What is the maximum amount of control individuals could have over their reactions to minor irritations?

Almost

no control
Almost

complete control
2

4

5

6

7

8

9

10

Compared to your family, friends and co-workers, how much control do you have over your reaction to minor irritations?

Much

Less

Same

Much

More

0
1
2

3

4

5

6

7

8

9

10

8. Some people feel stressed because they have too little free time. What is the maximum amount of control any person could have over the amount of free time available?

Almost

no control
Almost
complete control

\begin{tabular}{lllllllllll}
0 & 1 & 2 & 3 & 4 & 5 & 6 & 7 & 8 & 9 & 10 \\
\hline
\end{tabular}

Compared to your family, friends and co-workers, how much control do you have over the amount of free time you have?

Much

Less

Same

Much

More

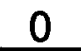

1

2

3

4

5

6

7

8

9 10 
page 5

9. Some people overeat because they use food for comfort when they are anxious or upset. What is the maximum possible control that the most strongwilled person has over eating for these reasons?

Almost

no control
Almost complete control

\begin{tabular}{lllllllllll}
0 & 1 & 2 & 3 & 4 & 5 & 6 & 7 & 8 & 9 & 10 \\
\hline
\end{tabular}

Compared to your family, friends, and co-workers, how much control do you have over eating for these reason?

Much

Less

Same

Much

More

\begin{tabular}{lllllllllll}
0 & 1 & 2 & 3 & 4 & 5 & 6 & 7 & 8 & 9 & 10 \\
\hline
\end{tabular}

10. One way to lose weight is to eat only low calorie foods. What is the maximum possible control anyone could have over the choice of foods?
Almost
Almost
no control
complete control

\begin{tabular}{lllllllllll}
0 & 1 & 2 & 3 & 4 & 5 & 6 & 7 & 8 & 9 & 10 \\
\hline
\end{tabular}

Compared to your family, friends and co-workers, how much control do you have the kinds of food you eat?

Much

Less

Same

Much

More

\begin{tabular}{lllllllllll}
0 & 1 & 2 & 3 & 4 & 5 & 6 & 7 & 8 & 9 & 10 \\
\hline
\end{tabular}


page 6

11. Some people are often around people who make them angry. What is the maximum possible control anyone could have over avoiding this type of situation?

Almost no control
Almost

complete control

\begin{tabular}{lllllllllll}
0 & 1 & 2 & 3 & 4 & 5 & 6 & 7 & 8 & 9 & 10 \\
\hline
\end{tabular}

Compared to your family, friends and co-workers, how much control do you have over avoiding this type of situation?

Much

Less

Same

Much

More

\begin{tabular}{lllllllllll}
0 & 1 & 2 & 3 & 4 & 5 & 6 & 7 & 8 & 9 & 10 \\
\hline
\end{tabular}

12. Some people gain weight because they have a habit of passive activities, such as watching TV or playing card games, instead of more strenuous activities. What is the maximum possible control any person can have over the activities he/she participates in?

Almost

no control
Almost complete control

\begin{tabular}{lllllllllll}
0 & 1 & 2 & 3 & 4 & 5 & 6 & 7 & 8 & 9 & 10 \\
\hline
\end{tabular}

Compared to your family, friends and co-workers, how much control do you have over the activities you participate in?

Much

Less

Same

Much

More

0

2

3

4

5

6

7

8

9

10 
page 7

13. Some people are happy because they have cheerful dispositions. What is the maximum possible control people have over their dispositions?

Almost no control
Almost complete control

\begin{tabular}{lllllllllll}
0 & 1 & 2 & 3 & 4 & 5 & 6 & 7 & 8 & 9 & 10 \\
\hline
\end{tabular}

Compared to your family, friends and co-workers, how much control do you have over your own disposition?

Much

Less

Same

Much

More

\begin{tabular}{lllllllllll}
0 & 1 & 2 & 3 & 4 & 5 & 6 & 7 & 8 & 9 & 10 \\
\hline
\end{tabular}

14. Some people have learned to use food to reward themselves. What is the maximum possible control any person could have over changing this behavior?
Almost
Almost
no control complete control

\begin{tabular}{lllllllllll}
0 & 1 & 2 & 3 & 4 & 5 & 6 & 7 & 8 & 9 & 10 \\
\hline
\end{tabular}

Compared to your family, friends and co-workers, how much control do you have over changing this type of behavior?

Much

Less

Same

Much

More

\begin{tabular}{llllllllllll}
0 & 1 & 2 & 3 & 4 & 5 & 6 & 7 & 8 & 9 & 10 \\
\hline
\end{tabular}


page 8

15. Some people gain weight because they do not like to exercise. What is the maximum possible control anyone could have over attitudes toward exercising?

Almost

no control
Almost

complete control

\begin{tabular}{lllllllllll}
0 & 1 & 2 & 3 & 4 & 5 & 6 & 7 & 8 & 9 & 10 \\
\hline
\end{tabular}

Compared to your family, friends, and co-workers, how much control do you have over your attitude toward exercising?

Much

Less

Same

Much

More

\begin{tabular}{lllllllllll}
0 & 1 & 2 & 3 & 4 & 5 & 6 & 7 & 8 & 9 & 10 \\
\hline
\end{tabular}

16. One way people may be able to keep from gaining weight is to eat only low calorie snack foods. What is the maximum possible control any person could have over types of snack foods eaten?
Almost
Almost
no control
complete control

\begin{tabular}{lllllllllll}
0 & 1 & 2 & 3 & 4 & 5 & 6 & 7 & 8 & 9 & 10 \\
\hline
\end{tabular}

Compared to your family, friends and co-workers, how much control do you have over the types of snack foods you eat?

Much

Less

Same

Much

More

0

12

3

4

5

6

7

8

9 10 


\section{PERSONAL INVENTORY}

In order for us to analyze the survey you have just completed, it is necessary for us to have the following personal information. Since your name does not appear anywhere on this form, you are assured that this information is completely anonymous.

Age

Sex

Height Weight

What is your ideal weight?

What is your approximate weight now compared to what it was 6 months ago? More Less Same

How much stress do you feel you have now?

Very little Moderate amount

Very much

Thank you again for taking the time to cooperate in this study. If you have any questions about the survey or its purpose and use, please contact Carolyn Wright, Psychology Dept., Portland State University, Portland, Oregon. (503)229-3923 